\title{
Corrupção e reforma institucional no Brasil, 1988-2008
}

\begin{tabular}{c}
\hline \hline Sérgio Praça \\
Escola de Economia \\
Fundação Getúlio Vargas \\
\hline \hline
\end{tabular}

Resumo: Como instituições políticas fomentam a corrupção? Como a publicização de escândalos de corrupção afeta a reforma dessas instituições? Este artigo toma o processo orçamentário brasileiro desde 1988 como um estudo de caso para ilustrar essas duas questões. Neste período, dois escândalos de corrupção envolvendo o processo orçamentário foram expostos: os "anões do orçamento" de 1988 a 1993 e os "sanguessugas" em 2006. O caso dos "anões" é um ótimo exemplo de como a centralização institucional, aliada à informalidade, resulta em corrupção. O caso dos "sanguessugas", por sua vez, ilustra como atores corruptos podem prosperar em um cenário institucional parcialmente descentralizado. Ambos os escândalos resultaram em reformas institucionais parciais e, até certo ponto, eficazes.

Palavras-chave: processo orçamentário; corrupção; mudança institucional; organização legislativa

\begin{abstract}
How do institutions foster corruption? How does the unveiling of corruption scandals affect institutional reform? This essay takes the Brazilian budget process from 1988 onwards as a case study in an attempt to answer both these questions. In this period, two corruption scandals in the budget process were uncovered: the "budget dwarves" in 1993-1994 and "budget leeches" in 2006. The first scandal is a classic example of how institutional centralization, coupled with informality, results in corruption; the second scandal illustrates how corrupt actors work within a partially decentralized institutional scenario. Both scandals resulted in partial, and somewhat effective, institutional reforms.
\end{abstract}

Keywords: budget process; corruption; institutional change; legislative organization 


\section{Introdução ${ }^{1}$}

A relação entre corrupção e instituições políticas tem sido extensamente analisada por economistas (BARDHAN, 1997; ROSE-ACKERMAN, 2006; MÉNDEZ e SEPÚLVEDA 2009) e cientistas políticos (TREISMAN 2007). Os mais diversos métodos são utilizados para avaliar essa relação. Há exemplos de surveys sobre a incidência potencial de atos corruptos (TRANSPARENCY INTERNATIONAL, 2007; ver a crítica de ABRAMO, 2005), de análise da infra-estrutura italiana (GOLDEN e $\mathrm{PICCl}, 2005$ ), de experimentos com policiais rodoviários no México (FRIED et al 2010), além de muitos outros. Embora seja uma literatura razoavelmente extensa, ainda há enorme controvérsia sobre, por exemplo, o desenho de instituições eleitorais que leva à maior ou menor incidência de corrupção (KUNICOVÁ e ROSE. ACKERMAN 2005; CHANG 2005; CHANG e GOLDEN 2007).

Este artigo propõe um olhar duplo sobre a relação entre corrupção e desenhos institucionais. Analisa, em um primeiro momento, o impacto das instituições na corrupção conforme manifestada no processo orçamentário e, posteriormente, o efeito indireto da publicização dos escândalos de corrupção no desenho institucional.

No período pós-constituinte brasileiro, dois escândalos de corrupção ligados ao processo orçamentário - os "anões do orçamento" em 1993/1994 e os "sanguessugas" em 2005/2006 - afetaram a agenda pública de propostas anticorrupção no país. As reformas no processo orçamentário resultantes das opções disponíveis nesta agenda pública, por sua vez, afetaram diretamente os padrões de corrupção no orçamento existentes no Brasil.

O texto explora inicialmente a corrupção como variável dependente, ao explicar de que modo a configuração institucional do processo orçamentário, centralizada ou descentralizada, afeta os padrões de corrupção descobertos. A segunda parte do artigo trata a corrupção como variável independente, ao considerar escândalos de corrupção no orçamento como uma das variáveis endógenas, que define a agenda de reformas institucionais presentes em períodos críticos.

\footnotetext{
${ }^{1}$ Este artigo é baseado na minha tese de doutorado em Ciência Política, defendida em Abril de 2010 sob orientação de Matthew M. Taylor, a quem sou grato pelos diversos comentários. Agradeço também os consultores de orçamento do Congresso Nacional - especialmente Carlos Marshall, Fernando Ramalho Bittencourt e Hélio Tollini - pelas entrevistas e material cedidos. Finalmente, agradeço ao parecerista anônimo por comentários que melhoraram o texto. Os erros e omissões são de minha inteira responsabilidade.
} 


\section{Definições e tipos de corrupção}

Pensar como certos desenhos institucionais podem levar a tipos diversos de corrupção impõe lidar com a literatura sobre centralização e descentralização institucional. Mas antes de considerar questões de reforma institucional, cabe discutir diversas definições de corrupção e quais delas são pertinentes para estudar corrupção no processo orçamentário brasileiro. De acordo com a definição mais utilizada, um ato corrupto implica o abuso de poder político para fins privados. É a definição adotada por organizações como o Banco Mundial e a Transparência Internacional (2007, p.xxi), bem como a imensa maioria dos analistas. Os escândalos dos "anões do orçamento" e "sanguessugas" estão contemplados nesta definição e é esta que adoto neste artigo.

Esses escândalos também se encaixam na definição recente de Glaeser e Goldin (2006, p.7), mais completa do que a primeira. De acordo com esses autores, o ato corrupto é formado por três itens. O primeiro é o pagamento a um funcionário público além de seu salário. O segundo é o fato de a ação associada a esse pagamento violar leis explícitas ou normas sociais implícitos. O terceiro é que a ação tem que resultar em perdas para a sociedade diretamente decorrentes de um ato corrupto ou decorrentes de um conjunto de pequenos atos ilícitos que tornam o sistema corrupto.

Finalmente, há uma terceira definição que vale a pena considerar, proposta por Mark Warren (2006). Segundo esta definição, há dois requisitos que, preenchidos, resultam em corrupção. O primeiro é que o ator político excluído do processo decisório devido à corrupção possa justificar sua inclusão com argumentos que são reconhecidos, mas violados, pelos atores corruptos que o excluem. O segundo requisito é que esta exclusão beneficie sistematicamente os atores corruptos incluídos e prejudique ao menos alguns dos excluídos do processo decisório.

De acordo com esta definição, o episódio dos "sanguessugas" não seria considerado corrupto. Afinal, tratava-se de parlamentares que destinavam emendas orçamentárias ligadas à área da saúde e compartilhavam, com prefeitos e burocratas do Ministério da Saúde, os ganhos corruptos. Não havia atores excluídos do processo político pelos "sanguessugas". A prerrogativa de emendar o orçamento na área da Saúde continuou sendo compartilhada pelos demais parlamentares ${ }^{2}$. A Tabela 1 sistematiza essa discussão.

\footnotetext{
2 Vale lembrar também que as afirmações sobre escândalos de corrupção aqui feitas têm como base os relatórios de comissões parlamentares de inquéritos dos "anões do orçamento" e "sanguessugas" (Congresso Nacional, 1994b; Congresso Nacional, 2006). São aproximações imperfeitas com base nas investigações realizadas e permitem comparar os escândalos apenas de modo incerto. A corrupção é um fenômeno de mensuração extremamente difícil. Assim, afirmações como a de Hunter (2008, p. 29), para quem o "mensalão do PT foi muito mais grave e sistemático do que a corrupção do presidente Fernando
} 
OPINIÃO PÚBLICA, Campinas, vol. 17, no 1, Junho, 2011, p.137-162

Tabela 1

Definições de corrupção e escândalos orçamentários no Brasil

\begin{tabular}{|l|c|c|}
\hline $\begin{array}{c}\text { Definição de corrupção engloba a } \\
\text { corrupção conforme praticada? }\end{array}$ & Anões do Orçamento & Sanguessugas \\
\hline $\begin{array}{l}\text { Nye 1967; Rose-Ackerman 1999; } \\
\text { Johnston 2005; Lambsdorff 2007; } \\
\text { Transparency International 2007 }\end{array}$ & Sim & Sim \\
\hline Glaeser e Goldin 2006 & Sim & Sim \\
\hline Warren 2006 & Sim & Não \\
\hline
\end{tabular}

Tendo adotado uma definição mínima para corrupção, é pertinente discutir (e aplicar aos casos em análise) alguns diferentes tipos ou formas. Mais adiante, analisarei a tipologia de Johnston (2005), ligada aos desenhos institucionais que incentivam cada forma de corrupção. Antes disso,vale considerar os três tipos propostos por Gambetta (2004, p. 5-13).

Para este autor, a corrupção consiste em um jogo envolvendo três agentes: o representante, o corruptor e o representado (fiduciary, corruptor and truster). Há três tipos de jogos mais comuns. No primeiro, há uma quebra explícita das regras pelo representante, de modo a favorecer o corruptor, em troca de um suborno. Um exemplo hipotético seria um cidadão (corruptor) pagar um funcionário da Polícia Federal (representante) para obter um passaporte diplomático - ou seja, um serviço que ele não deveria fazer. Isso feriria os demais cidadãos (representados) que não pagaram o suborno e têm apenas um passaporte comum.

O segundo tipo consiste em o representante agir de acordo com as regras, fazendo exatamente o que lhe compete fazer, apenas se houver suborno oferecido pelo corruptor. Um exemplo seria o cidadão (corruptor) conseguir obter um passaporte comum apenas através do pagamento corrupto. Por fim, o terceiro tipo de corrupção ocorre quando o representante, subornado pelo corruptor, age de acordo com as regras e faz algo que está implicitamente autorizado a fazer, mas que não é sua obrigação ${ }^{3}$. Seria o caso, em um exemplo hipotético, de um cidadão (corruptor) conseguir seu passaporte comum em dois dias quando o tempo previsto para isso é seis meses.

Como esses três tipos se relacionam aos casos de corrupção no orçamento brasileiro? Os dois primeiros tipos descritos estiveram presentes tanto no escândalo

Collor", são demasiadamente subjetivas e não encontram espaço nesta análise sobre corrupção no processo orçamentário brasileiro. Para uma abordagem mais completa sobre a corrupção no Brasil atual, ver Taylor (2009).

3 Essa autorização implícita decorreria de legislação vaga, pouco detalhada. Huber e Shipan (2002) concordam que o detalhamento legislativo diminui a autonomia de ação dos burocratas. Portanto, plausivelmente, diminuiria as oportunidades corruptas. Golden (2003) defende a perspectiva contrária. 
dos "anões do orçamento" quanto no escândalo dos "sanguessugas". O primeiro tipo - quebra explícita das regras pelo representante mediante suborno - se manifestou no escândalo dos "anões do orçamento" quando, por exemplo, o relatorgeral da comissão beneficiava organizações sociais pertencentes à rede corrupta4. No caso dos "sanguessugas", esse tipo de corrupção ocorria quando a prefeitura pertencente à rede corrupta fraudava licitações para beneficiar a Planam, empresa que fabricava as ambulâncias a serem compradas pelo município.

O segundo tipo de corrupção - quando o representante age de acordo com as regras apenas mediante suborno - ocorreu no caso dos "anões" quando o relatorgeral da comissão orçamentária era subornado por um parlamentar para aprovar uma emenda orçamentária específica. No escândalo dos "sanguessugas", esse tipo ocorria quando um parlamentar apresentava emendas para a área de saúde mediante suborno da empresa de ambulâncias ${ }^{5}$.

Tendo determinado a definição de corrupção em uso neste artigo, bem como os diversos tipos de corrupção a considerar nos escândalos orçamentários estudados, cabe agora ligar os tipos de corrupção aos incentivos institucionais que os tornam mais ou menos prováveis. Johnston (2005) propõe uma tipologia interessante e, para o caso aqui estudado, mais útil do que a de Gambetta (2004), pois liga incentivos institucionais aos tipos possíveis de corrupção.

Há, de acordo com Johnston (2005, p. 3), quatro tipos básicos de corrupção política. O primeiro é relacionado à "influência do mercado" e envolve esforço por parte de interesses privados (empresas, geralmente) para obter acesso e influência dentro de processos políticos bem institucionalizados. É o tipo de corrupção mais característico de democracias desenvolvidas. O segundo é a corrupção de um "cartel de elite". Ela ocorre dentro de, e ajuda a sustentar, redes de elites políticas, econômicas, burocráticas etc. Ajuda a manter a hegemonia dessas elites em um contexto de competição política crescente e instituições políticas moderadamente institucionalizadas.

O terceiro tipo é a corrupção de "oligarcas e clãs", que ocorre em contextos arriscados, freqüentemente violentos, em que há oportunidades políticas e econômicas em expansão dentro de instituições fracas. É dominado por atores com poder pessoal, que atraem militantes e seguidores não por causa do cargo que ocupam, mas por carisma ou ameaças. Por fim, o quarto tipo é a corrupção de burocratas. Nesse tipo, políticos e burocratas de sua confiança assaltam o

\footnotetext{
4 O deputado federal João Alves, quando relator-geral da comissão orçamentária em 1990, “"passou a decidir a inclusão de novas despesas no orçamento: construção de pontes, escolas, hospitais, verbas para programas sociais, recursos para grandes obras. Além disso, poderia incluir em seu relatório o aumento da dotação em despesas já previstas no projeto do Executivo. O deputado tornou-se dono de um concorrido balcão, freqüentado por políticos e empreiteiras" (KRIEGER et. al, 1994, p. 26).

5 Nem sempre, de acordo com o relatório da CPI que investigou o caso dos "sanguessugas", a apresentação de emendas ocorria mediante suborno (CONGRESSO NACIONAL, 2006).
} 
orçamento com impunidade. Há pouquíssima competição política e a institucionalização política e econômica são baixíssimas, resultando que oportunidades econômicas são escassas e disputadas com afinco.

Esses quatro tipos de corrupção poderiam ser considerados em um continuum descentralização-centralização institucional. Os efeitos deletérios para o sistema econômico e político de cada tipo são variados, embora a literatura tenda a considerar mais custosa a corrupção centralizada (KLITGAARD 1988; SHLEIFER e VISHNY 1993; exceções são GERRING e THACKER 2004; FISMAN e MIGUEL 2008, p. 44-45).

Considero que a corrupção centralizada ocorre quando um agente político (ou um grupo "fechado" de agentes, como os membros de uma comissão parlamentar) controla o acesso ao esquema de corrupção. É o que ocorre, por exemplo, quando um traficante controla um bairro e exige propina dos comerciantes. Outro exemplo é o esquema dos "anões do orçamento". Os "anões" eram o grupo político que controlava o processo orçamentário no Brasil de 1989 a 1993 a partir da Comissão Mista de Orçamento, interagindo de modo corrupto tanto com integrantes do Executivo quanto com certas empreiteiras. Assemelha-se, na tipologia de Johnston (2005), à corrupção de um "cartel de elite", pois o pertencimento a esta rede corrupta requeria a amizade dos integrantes já existentes - assim, todos os integrantes estavam informados de pelo menos a imensa maioria dos atos corruptos praticados pela rede.

A corrupção descentralizada, por sua vez, existe quando vários agentes políticos, sem coordenação, agem de modo corrupto. É o que ocorre, por exemplo, quando vários traficantes concorrem e exigem, separadamente, propina dos comerciantes. Outro exemplo é o esquema dos "sanguessugas" do orçamento. Os "sanguessugas" foram um grupo composto por 72 parlamentares, desmascarados em 2006, que destinavam emendas orçamentárias ligadas à área da saúde e compartilhavam, com prefeitos e burocratas do Ministério da Saúde, os ganhos corruptos obtidos a partir de licitações municipais irregulares ligadas a essas emendas. Assemelha-se, na tipologia de Johnston (2005), à corrupção sujeita à "influência do mercado", pois cada parlamentar tinha contato com uma prefeitura específica, que fraudaria as licitações de modo a beneficiar a empresa corrupta. Deste modo, o pertencimento à rede corrupta dos "sanguessugas" era mais aberto do que à rede dos "anões do orçamento".

Considerando isso, a próxima seção explica a vulnerabilidade a atos corruptos do desenho orçamentário brasileiro. 


\section{0 que explica a corrupção no orçamento?}

Quais são, na etapa legislativa do processo orçamentário brasileiro, os desenhos institucionais mais vulneráveis à corrupção? É pertinente expor quatro argumentos sobre interferência legislativa e corrupção no orçamento orientados pela discussão teórica realizada acima.

O primeiro é: mantidos constantes outros fatores, o Legislativo será um possível locus de corrupção no orçamento caso tenha a prerrogativa de adicionar novas despesas à proposta orçamentária enviada pelo Executivo. Afinal, para que se concretize, a corrupção no orçamento necessita de uma oportunidade inicial para que seja incluída no orçamento a previsão para certa despesa com fins corruptos. A corrupção será concretizada posteriormente, no momento da execução orçamentária. Mas a importância da etapa inicial, na qual agentes privados e agentes políticos corruptos atuam em conluio para incluir certa despesa para fins corruptos, não pode ser subestimada.

Caso os parlamentares não possam propor novas despesas, o Executivo com seus ministérios e burocracias - concentrará o planejamento definitivo e a execução do orçamento, sendo assim o único possível locus político de corrupção no orçamento. Em países com este desenho institucional, o agente privado corrupto não negociará despesas potencialmente desviadas para corrupção com os parlamentares. Assim, o Executivo será o único locus de corrupção no processo orçamentário, pois a ele cabe formular e executar o orçamento. Nesse sentido, Isaksen (2005, p.5) afirma que "caso o Legislativo não esteja envolvido no planejamento orçamentário, a preparação do orçamento caberá apenas ao Executivo - mais especificamente, à equipe técnica pertencente ao médio e baixo escalão da burocracia."

De 1988 a 1997, parlamentares brasileiros podiam propor emendas sem limite de valor. Durante o processo orçamentário de 1997, a coalizão liderada pelo Executivo começou a estabelecer um limite informal de valor para as emendas orçamentárias. Esta solução foi consagrada formalmente partir da resolução congressual 1/2001, onde definiu-se que a lei orçamentária anual estabeleceria um limite monetário para o total de emendas propostas por cada deputado ou senador. Neste quesito, o Brasil está em posição intermediária, nem típica (seria este o caso se o Legislativo pudesse propor emendas sem limite de valor) nem idiossincrática (seria este o caso se o Legislativo não pudesse propor novas despesas).

O segundo argumento é: mantidos constantes outros fatores, orçamentos analisados por apenas uma casa legislativa (ou em conjunto por ambas) tendem a ser mais vulneráveis à corrupção do que orçamentos que tramitam por duas casas legislativas. 
Se as condições institucionais de monopólio e autonomia são aquelas sob as quais a corrupção tende a prosperar (KLITGAARD, 1988), é plausível imaginar que, quando duas casas legislativas tratam de assuntos orçamentários, a corrupção em uma delas é limitada, ainda que informalmente, pela outra. Um agente privado corrupto que queira subornar parlamentares para que estes incluam emendas de seu interesse no orçamento (e mais tarde pressionam o Executivo para a liberação das verbas), terá seu custo político e econômico multiplicado para obter benefícios corruptos. Sob a perspectiva do agente político corrupto, os custos também aumentam. O parlamentar corrupto estará sujeito à análise do orçamento pela outra casa legislativa, onde sua interferência corrupta poderá ser revisada ou eliminada. Desde 1969 o Congresso Nacional brasileiro aprecia e vota, em sessão mista, o orçamento federal.

O terceiro argumento é: mantidos constantes outros fatores, Legislativos compostos por diversas comissões orçamentárias setoriais, sem uma comissão orçamentária final com poder para definir as despesas finais, serão menos vulneráveis às oportunidades de corrupção.

Se uma comissão parlamentar monopoliza a análise do orçamento, seus integrantes têm mais credibilidade para negociar/intermediar atos corruptos com agentes privados do que os demais parlamentares. Agentes privados corruptos têm menos custos para agir de modo ilegal se as oportunidades iniciais de corrupção estiverem concentradas em uma única comissão, em vez de dispersas em várias. Podemos imaginar, por exemplo, que em certo Legislativo há uma comissão orçamentária responsável por analisar despesas e receitas totais, e esta comissão compartilha poder com diversas comissões setoriais que têm a prerrogativa de definir os orçamentos específicos dos ministérios correspondentes. $O$ agente privado corrupto pode negociar uma emenda para fins corruptos na comissão setorial, mas não terá a garantia - a qual o parlamentar corrupto da comissão setorial não poderá Ihe fornecer - de que aquela emenda sobreviverá ao escrutínio da comissão orçamentária final. Desde 1969, como já foi dito, temos a Comissão Mista do Orçamento como responsável pela interferência legislativa neste tema.

Por fim, o quarto argumento é: mantidos constantes outros fatores, parlamentos com comissões autônomas para decidir a inclusão definitiva de novas despesas sem o escrutínio do plenário tendem a oferecer mais oportunidades para a corrupção do que parlamentos nos quais o plenário tem a prerrogativa de apreciar ou rejeitar novas despesas.

Se as instâncias decisórias consagradas em qualquer Legislativo são as comissões e o plenário, a autonomia da comissão orçamentária em relação ao plenário é um aspecto relevante a ser considerado. Uma comissão orçamentária com o monopólio da apreciação de emendas e autonomia para incluí-las no orçamento sem a manifestação do plenário tende a ser procurada por agentes 
privados corruptos, pois os parlamentares que integrarem essa comissão terão, além das oportunidades para incluir a emenda com fins corruptos, credibilidade suficiente para convencer o agente privado corrupto de que o plenário não derrubará a emenda.

No Brasil, a resolução congressual 1/1991 definiu, em seu artigo 24, que "o parecer da Comissão Mista de Orçamento sobre as emendas será conclusivo e final, salvo requerimento assinado por $1 / 10$ dos congressistas para que a emenda seja submetida a votos". Embora essa resolução já tenha sido revogada, artigo semelhante continuou constando das resoluções congressuais sobre orçamento subseqüentes. A votação das emendas orçamentárias em plenário se dá na votação da lei orçamentária anual, não sendo previsto, exceto pela situação descrita no artigo acima, momento de votação específico para as emendas dos parlamentares.

O desenho orçamentário mais vulnerável à corrupção é, portanto, o seguinte: i) o Legislativo pode propor novas despesas ao orçamento; ii) o Legislativo tem a prerrogativa de alterar certas regras do processo orçamentário sem precisar mudar a Constituição; iii) apenas uma casa parlamentar (ou ambas conjuntamente) analisam o orçamento; iv) apenas uma comissão (de deputados, de senadores ou mista) analisa o orçamento; v) esta comissão orçamentária é relativamente autônoma em relação ao plenário no que se refere à apreciação de emendas parlamentares. 
OPINIÃO PÚBLICA, Campinas, vol. 17, no 1, Junho, 2011 , p.137-162

Tabela 2

Desenhos orçamentários e vulnerabilidade à corrupção no Brasil, 1946-2008

\begin{tabular}{|l|l|l|l|l|}
\hline & CF/1946 & $\begin{array}{l}\text { Regime Militar } \\
(\mathbf{1 9 6 7 / 1 9 6 9 ) *}\end{array}$ & CF/1988 (1988) & $\begin{array}{l}\text { CF/1988 + } \\
\text { Resoluções (2008) }\end{array}$ \\
\hline $\begin{array}{l}\text { O legislativo pode } \\
\text { emendar } \\
\text { orçamento? }\end{array}$ & $\begin{array}{l}\text { Sim, } \\
\text { quase sem } \\
\text { limites }\end{array}$ & Não & $\begin{array}{l}\text { Sim, com limites } \\
\text { expandidos, } \\
\text { entre 1988 e } \\
1993, \text { por atos } \\
\text { informais e } \\
\text { corruptos }\end{array}$ & Sim, com limites \\
\hline $\begin{array}{l}\text { Apenas uma casa } \\
\text { legislativa analisa } \\
\text { orçamento? }\end{array}$ & Não & Sim & Sim & Sim \\
\hline $\begin{array}{l}\text { Apenas uma } \\
\text { comissão legislativa } \\
\text { analisa orçamento? }\end{array}$ & Não & Sim & Sim & Sim \\
\hline $\begin{array}{l}\text { Comissão } \\
\text { orçamentária é } \\
\text { autônoma em } \\
\text { relação ao plenário? }\end{array}$ & Pouco & Sim & $\begin{array}{l}\text { Regimento } \\
\text { Interno } \\
\text { determinará** }\end{array}$ & Sim \\
\hline
\end{tabular}

* Constituição Federal de 1967 e Emenda Constitucional 1/1969

** A Resolução 1/1991 do Congresso Nacional estipulou que parecer da Comissão Mista de Orçamento sobre emendas seria conclusivo e final, salvo manifestação de 1/10 do plenário de ambas as casas legislativas.

Dado o desenho institucional consagrado pela Constituição Federal de 1988, não é de espantar que o Brasil tenha se deparado com dois escândalos de corrupção no orçamento em 1993/1994 e 2005/2006, embora com configurações e efeitos econômicos bastante distintos.

\section{O quê a corrupção no processo orçamentário explica?}

Nesta seção, analiso como a publicização desses escândalos afetou as escolhas sobre instituições orçamentárias no período democrático recente.

Em 1990, o deputado federal João Alves (PPR), Relator-Geral do processo orçamentário daquele ano, tinha liberdade para propor emendas orçamentárias com novos projetos. Aproveitava-se de um vasto vazio institucional resultante da falta de uma resolução congressual que regulasse a tramitação do orçamento; afinal, a Constituição Federal de 1988 tratava apenas das regras básicas. Alves propôs um parecer preliminar sobre a proposta orçamentária do Executivo com o conteúdo que queria, sem trechos obrigatórios nem análise detalhada da conjuntura econômica. O mais famoso "anão do orçamento" tinha também a prerrogativa de avaliar as emendas individuais propostas por seus colegas parlamentares, sem fixar um limite de valor máximo e sem autorizar emendas propostas coletivamente. 
Sozinho, Alves podia, por fim, reestimar à vontade a receita prevista pelo Executivo para o ano seguinte.

Dezessete anos depois, este cenário era impossível. O Relator-Geral de 2007, José Pimentel (PT), não pôde propor "emendas de relator" que colocassem novos projetos no orçamento. Seguiu os 161 artigos das 38 páginas da Resolução 1/2006 do Congresso Nacional, que dispõe sobre a tramitação do projeto orçamentário no Legislativo. Pimentel propôs um parecer preliminar de 75 páginas, com duas partes, extremamente detalhado. Parlamentares propuseram emendas individuais e emendas coletivas através das comissões da Câmara dos Deputados e Senado Federal e das bancadas estaduais. Definiu-se um valor máximo para cada parlamentar emendar individualmente o orçamento, após negociações com líderes partidários. A Resolução 1/2006 fixou em 25 o número de emendas individuais a serem propostas por cada parlamentar. Pimentel teve que trabalhar com o senador Francisco Dornelles (PP-RJ), Relator da Receita, para definir a reestimativa em relação à proposta do Executivo.

Observa-se que as mudanças institucionais no processo orçamentário brasileiro desde 1988 foram notáveis. Boa parte dessas alterações teve a corrupção dos "anões" ou dos "sanguessugas" como indutora. Antes de analisar como isso ocorreu, é necessário esclarecer quais são os interesses políticos que orientam o desenvolvimento e estabilidade de instituições orçamentárias no Brasil.

De acordo com Schickler (2001, p.5), cinco tipos de interesses coletivos presentes no Legislativo - diferentes e parcialmente contraditórios - podem motivar o desenho de instituições legislativas e orçamentárias. São eles: i) interesse na reeleição: parlamentares incumbentes tendem a criar e preservar dispositivos institucionais que aumentam suas chances de se reeleger; ii) interesse no Legislativo como ator coletivo: todos os parlamentares estão potencialmente interessados em aumentar a capacidade, poder e prestígio do Legislativo como instituição; iii) interesses nos postos de poder institucional: parlamentares que ocupam posições institucionais de grande poder tendem a querer conservá-las, enquanto os que não têm acesso a essas posições institucionais tendem a querer diminuir as prerrogativas e poderes inerentes a esses postos; iv) interesses partidários: membros do partido majoritário no Legislativo podem discordar de desenhos institucionais que interessem aos integrantes do partido minoritário; v) interesses em políticas públicas: esse tipo de interesse se firma analiticamente na conexão entre instituições e resultados políticos. Certas instituições podem favorecer determinados resultados políticos em detrimento de outros.

Os três primeiros interesses assinalados por Schickler (2001) parecem ser razoavelmente universais e podem ser aplicados ao caso brasileiro. O interesse na reeleição manifesta-se em discussões sobre prerrogativas de emendamento e mecanismos para melhorar a execução das emendas sob a ótica dos 
parlamentares. A noção de que ter emendas orçamentárias individuais executadas é um dos mais importantes fatores para conseguir a reeleição para o Legislativo (ou continuar a carreira política dentro do distrito eleitoral brasileiro, o estado) é bastante presente tanto na literatura acadêmica (PEREIRA e RENNÓ, 2003) quanto entre os parlamentares (CARVALHO 2003, p.154-155).

$O$ interesse no Legislativo como ator coletivo está presente em qualquer parlamento. $O$ interesse nos postos de poder institucional é o principal interesse associado à organização da Comissão Mista de Orçamento. Trata-se da vontade de manter o acesso a cargos institucionais, internos ao Legislativo, que permitem mobilizar recursos, organizar pequenas coalizões a favor ou contra certa proposta e dialogar com ministros e outros membros do Executivo.

Quanto aos interesses partidários, parece mais frutífero no caso brasileiro substituí-los por interesses referentes ao pertencimento à coalizão, pois a clivagem política que define interesses dentro do Legislativo, acesso a postos do Executivo e outros aspectos, é o pertencimento ou não à coalizão formada pelo presidente. Isto não significa que a coalizão é formada sem levar em conta interesses partidários. Ao contrário: são os partidos políticos que resolvem problemas de coordenação entre os parlamentares e o Executivo, organizando demandas políticas diversas e informando deputados sobre as propostas legislativas do Executivo (FIGUEIREDO e LIMONGI, 1999). No entanto, a divisão do Legislativo em "coalizão" e "oposição" é analiticamente frutífera, dado que embates políticos freqüentemente opõem esses interesses, enquanto interesses de diversos partidos que pertencem à coalizão, por exemplo, tendem a ser mais harmônicos.

Com relação aos interesses em políticas públicas como determinantes de interesses por desenhos institucionais, trata-se de algo que pouco aparece nas discussões sobre reforma orçamentária no Brasil.

A estratégia de execução orçamentária utilizada pelo Executivo brasileiro no período pós-1988 é fundamental para explicar como esses interesses interagem de modo a determinar as preferências por certas instituições em vez de outras. Explica, portanto, por que parlamentares da coalizão devem, em tese, defender limites ao emendamento, à organização centralizada da Comissão Mista de Orçamento e o Orçamento Autorizativo. Os parlamentares da oposição, por sua vez, devem defender emendamento ilimitado, a descentralização da comissão orçamentária e o Orçamento Impositivo.

A interação entre a execução de emendas orçamentárias individuais e a discricionariedade do Executivo em realizar os gastos previstos por essas emendas (ou seja, o Orçamento Autorizativo) é a dinâmica que sustenta o desenho institucional. Há três atores políticos envolvidos: parlamentares da coalizão liderada pelo Executivo, parlamentares da oposição e o Executivo. 
O Orçamento Autorizativo fornece vantagem distributiva para os membros da coalizão, pois permite que parlamentares pertencentes à coalizão governista tenham mais emendas orçamentárias individuais executadas do que os oposicionistas.

\begin{abstract}
"a execução das emendas individuais é pautada por critérios políticos. As emendas dos deputados filiados a partidos da coalizão do governo têm maiores chances de serem executadas do que as dos demais parlamentares. Contudo, parte das emendas de deputados da oposição também é executada e parte das emendas dos parlamentares que votam com o governo não é executada" (FIGUEIREDO e LIMONGI, 2008, p.104, grifo meu).
\end{abstract}

\title{
Períodos críticos e escândalos de corrupção no processo orçamentário
}

A análise do impacto da corrupção na evolução de regras orçamentárias no Brasil ao longo das duas últimas décadas exige olhar cuidadoso sobre os momentos $\operatorname{críticos}^{7}$ nos quais decisões importantes a respeito dessas instituições foram seriamente consideradas e, então, descartadas ou aprovadas.

Antes de 1995 , o processo orçamentário brasileiro oscilava entre a irrelevância (pois a hiperinflação tornava os gastos extremamente difíceis de controlar e estimulavam brigas entre ministérios, como mostra Pinheiro [1996]) e a corrupção (pois de 1988 a 1993 ocorreu danosa captura corrupta da Comissão Mista de Orçamento por um grupo de parlamentares). Uma comissão parlamentar de inquérito (CPI) foi instalada em outubro de 1993 para investigar o enriquecimento ilícito de alguns integrantes da Comissão Mista de Orçamento. Com duração de três meses, a CPI dos anões do orçamento investigou 43 parlamentares, dos quais 14 foram inocentados, investigações adicionais foram sugeridas para 11 e 18 tiveram a cassação recomendada. Quatro parlamentares renunciaram e seis foram cassados.

Em janeiro de 1994, o relatório final da CPI do Orçamento sugeriu 23 mudanças referentes ao processo orçamentário. Na mesma época, o governo federal preparou e implementou diversas medidas macroeconômicas com o intuito de acabar com a hiperinflação no Brasil, especialmente o Plano Real em julho de

\footnotetext{
6 Esta citação se sustenta mesmo em anos mais recentes, não considerados no livro de Figueiredo e Limongi (2008). De acordo com Perezino (2008), a execução das emendas individuais dos partidos pertencentes à base de sustentação do governo é, na média entre 2004 e 2007, 45\% superior a dos partidos de oposição.

7 Não se trata, aqui, do conceito de critical junctures, às vezes traduzido para o português como "momento crítico". Quero apenas destacar a existência de alguns momentos nos quais reformas orçamentárias estiveram mais presentes na agenda pública e congressual. Para uma análise recente do conceito de critical junctures, ver Capoccia e Kelemen (2007).
} 
1994. O parecer preliminar do relator-geral do orçamento para 1994 - a peça legislativa mais relevante para o processo além da própria lei orçamentária -, deveria ter sido aprovado no fim de 1993, mas foi aprovado apenas no fim de agosto de 1994 devido à prioridade dada pelo governo às reformas macroeconômicas.

Em novembro de 1994, a Resolução 2/1994 foi aprovada às pressas para tratar das regras do orçamento do ano seguinte. Foi uma resolução de transição, cujo objetivo era assegurar as preferências do Executivo no processo orçamentário até Fernando Henrique Cardoso, ex-ministro da Fazenda, eleger-se presidente e seu Plano Real se consolidar. Quatro meses depois, os presidentes da Câmara dos Deputados e Senado Federal instalaram um grupo de trabalho para rever as regras orçamentárias, liderado pelo senador José Fogaça (PMDB). A resolução congressual proposta por este grupo foi aprovada em setembro de 1995, a tempo de regulamentar o processo que resultou no orçamento para 1996. Há grande consenso na literatura de que esta Resolução 2/1995 resultou da CPI (BARBOSA 2006, p.58; VIEIRA 2008, p.16; FIGUEIREDO e LIMONGI 2008, p.49).

Quase dez anos depois, em março de 2005, um ofício do deputado federal Paulo Bernardo (então presidente da Comissão Mista de Orçamento) enviado para os presidentes da Câmara dos Deputados e Senado Federal tratava de diversos temas relativos à reforma orçamentária. Bernardo diagnosticou um "distanciamento da execução orçamentária em relação à autorização legislativa expressa na lei orçamentária, dada a idéia de que o orçamento aprovado tem caráter autorizativo" e um "contingenciamento discricionário da execução orçamentária". A partir deste ofício, uma comissão de deputados e senadores foi encarregada de organizar reuniões com membros do Executivo e parlamentares em geral sobre diversos itens da reforma orçamentária. Esta comissão não teve sucesso em formar consenso em torno de uma proposta de mudança de regras orçamentárias, apesar do aparente esforço do relator Ricardo Barros (PP, oposição).

O período crítico de 2005-2006, iniciado com a instalação desta comissão relatada por Barros, terminou com a aprovação da Resolução 1/2006 em novembro daquele ano, graças à perseverança desse deputado. O próprio Barros (2007, p.12. 14) relata sua estratégia: "Travei uma batalha para que o projeto fosse apreciado no Congresso. Como principal arma, eu me vali da obstrução, que me era facultada, como a qualquer congressista, pelo artigo 28 do Regimento Comum, que exige o quórum mínimo de um sexto dos parlamentares de cada Casa durante o transcurso das sessões do Congresso. A obstrução teve início na votação do Orçamento de 2006 e a verdade é que sempre tive o apoio de todos, inclusive do presidente do Senado, Renan Calheiros, que nunca se furtou aos elogios ao projeto de Resolução, mas era dificílimo ver a matéria ser votada porque tais alterações contrariavam os mais diversos interesses. (...) Em novembro de 2006, foi convocada uma sessão 
para votar créditos que permitiriam o aumento do poder Judiciário, TCU e Ministério Público. A pressão era enorme, mas mantivemos a obstrução. Nos dias subseqüentes, recebi mais de 3.500 e-mails dos servidores e sindicatos envolvidos reclamando da obstrução. Desta vez não cedi aos apelos sob o compromisso de que a resolução seria votada antes do projeto de lei orçamentária para 2007, o que finalmente aconteceu em 28 de novembro de 2006".

É bastante plausível que o insucesso de Barros teria ocorrido também no fim de 2006 se não fosse a instalação da CPI das Ambulâncias/Sanguessugas em junho daquele ano, investigando a corrupção descentralizada no processo orçamentário, envolvendo ao menos 72 parlamentares. O relatório final da CPI foi publicado em agosto de 2006. Isto colocou o tema "processo orçamentário" novamente na mídia e ajudou a impedir que o Executivo e demais parlamentares freassem as mudanças propostas na resolução de Ricardo Barros.

Entre 1988 e 2008, onze decisões foram tomadas - algumas delas em mais de um momento - sobre a organização da etapa legislativa do processo orçamentário. Quatro das sete decisões sobre emendamento orçamentário tiveram alguma associação com escândalos de corrupção, algo que também afetou três das quatro decisões sobre a organização da Comissão Mista de Orçamento (ver Tabelas 3 e 4$)$.

\section{Tabela 3}

Corrupção e escolhas sobre emendamento orçamentário, 1988-2008

\begin{tabular}{|l|c|c|c|}
\hline & $\begin{array}{c}\text { Caso associado à } \\
\text { corrupção? }\end{array}$ & $\begin{array}{c}\text { Associado à } \\
\text { corrupção dos anões? }\end{array}$ & $\begin{array}{c}\text { Associado à } \\
\text { corrupção dos } \\
\text { sanguessugas? }\end{array}$ \\
\hline $\begin{array}{l}\text { Número de emendas } \\
\text { individuais }\end{array}$ & $\operatorname{Sim}$ & $\operatorname{Sim}$ & $\operatorname{Sim}$ \\
\hline $\begin{array}{l}\text { Natureza de } \\
\text { emendas individuais }\end{array}$ & $\operatorname{Sim}$ & $\operatorname{Sim}$ & $\mathrm{Sim}$ \\
\hline $\begin{array}{l}\text { Número e atores: } \\
\text { emendas de bancada } \\
\text { estadual }\end{array}$ & $\operatorname{Sim}$ & Não & Não \\
\hline $\begin{array}{l}\text { Número e atores: } \\
\text { emendas de } \\
\text { comissão }\end{array}$ & Não & Não & Não \\
\hline $\begin{array}{l}\text { Valor de emendas } \\
\text { coletivas }\end{array}$ & Não & Não & Sim \\
\hline $\begin{array}{l}\text { Natureza de emendas } \\
\text { coletivas: emendas } \\
\text { de bancada estadual }\end{array}$ & Sim & Não & Não \\
\hline $\begin{array}{l}\text { Natureza de emendas } \\
\text { coletivas: emendas } \\
\text { de comissão }\end{array}$ & Não & & \\
\hline
\end{tabular}


OPINIÃO PÚBLICA, Campinas, vol. 17, no 1, Junho, 2011, p.137-162

Tabela 4

Corrupção e escolhas sobre a organização da Comissão Mista de Orçamento, 1988-2008

\begin{tabular}{|l|c|c|c|}
\hline & $\begin{array}{l}\text { Caso pode ser } \\
\text { associado à } \\
\text { corrupção? }\end{array}$ & $\begin{array}{l}\text { Associado à } \\
\text { corrupção dos anões? }\end{array}$ & $\begin{array}{l}\text { Associado à } \\
\text { corrupção dos } \\
\text { sanguessugas? }\end{array}$ \\
\hline $\begin{array}{l}\text { Poder de Relator- } \\
\text { Geral para emendar } \\
\text { orçamento }\end{array}$ & $\begin{array}{c}\text { Sim, sobretudo em } \\
1995\end{array}$ & Sim & Não \\
\hline $\begin{array}{l}\text { Poder de Relator- } \\
\text { Geral para estimar } \\
\text { receita }\end{array}$ & $\begin{array}{c}\text { Sim, sobretudo em } \\
1995\end{array}$ & Sim \\
\hline $\begin{array}{l}\text { CMO como } \\
\text { responsável pelo } \\
\text { orçamento }\end{array}$ & $\begin{array}{l}\text { Sim, muito, mas } \\
\text { apenas em 1995 }\end{array}$ & Sim & Não \\
\hline $\begin{array}{l}\text { CMO e relação } \\
\text { interna entre Relator- } \\
\text { Geral e Relatores } \\
\text { Setoriais }\end{array}$ & Não & Não & Não \\
\hline
\end{tabular}

\section{A prerrogativa de emendamento do Relator-Geral da CMO}

Esta seção trata de um caso em que a publicização de escândalos de corrupção no orçamento foi crucial para a mudança institucional: o poder do relator-geral da Comissão Mista de Orçamento para emendar o orçamento. Também analisado um caso em que a corrupção importou pouco para o processo de mudança: a relação do relator-geral do processo orçamentário com os relatores setoriais. Ambas as mudanças estão, em seguida, associadas à tipologia de Johnston (2005), especialmente no que se refere às expectativas do autor sobre mudança institucional.

As emendas de relator-geral foram, no período dos "anões do orçamento", um dos pilares do esquema de corrupção organizado por esses parlamentares. 0 ex-deputado federal João Alves de Almeida (PPR) acumulou, ilegalmente, US\$30,5 milhões entre 1989 e 1992. Junto com outros parlamentares de baixa estatura, Alves controlou a Comissão Mista de Orçamento nesse período, tendo sido relatorgeral da lei orçamentária em 1990, e muito influente mesmo sem ocupar esse posto. Foi, sem dúvida, o líder dos "anões do Orçamento".

João Alves, em diversos cargos importantes na Comissão Mista do Orçamento, "passou a decidir a inclusão de novas despesas no orçamento: construção de pontes, escolas, hospitais, verbas para programas sociais, recursos para grandes obras. Além disso, poderia incluir em seu relatório o aumento da dotação em despesas já previstas no projeto do Executivo. O deputado tornou-se 
dono de um concorrido balcão, freqüentado por políticos e empreiteiras" (KRIEGER et al, 1994, p.26). Conforme o próprio parlamentar afirmou em depoimento à CPI, "o dinheiro do orçamento só saía se alguém descontingenciasse, e José Carlos Alves dos Santos, como Diretor do Orçamento no Executivo, era o intermediário" (CONGRESSO NACIONAL, 1994a, p.4). Afirmou também que José Carlos Alves dos Santos disse que recebia pedidos de parlamentares e de prefeitos que solicitavam o descontingenciamento de recursos destinados às suas respectivas regiões. Conhecia também empresas particulares, através de comentários de parlamentares, que agilizavam a liberação de verbas e cobravam comissões que variavam de 5\% a $15 \%$.

Um dos principais recursos utilizados por Alves era a prerrogativa de propor emendas como relator-geral. Um exemplo é a emenda 955.6 de 1990 (CONGRESSO NACIONAL, 1990, p.34-65). Foi aprovada como emenda de relator-geral "face à importância do subprojeto". Trata de infraestrutura urbana em Lauro de Freitas, município baiano. A emenda está no item "investimentos" do Ministério da Ação Social, um dos notoriamente corruptos da época (KRIEGER et al, 1994, p.109). O objetivo é "promover a recuperação e expansão da infra-estrutura básica de centros urbanos". Não há como provar que esta emenda, especificamente, foi utilizada para fins corruptos. Serve apenas para ilustrar a lógica da autonomia do relator-geral para incluir projetos - ligados ou não a atos corruptos - sem a concordância de outros parlamentares.

O número de emendas de relator-geral oscilava bastante ano a ano - em 1988, 301 ; em 1993, 609 (CONGRESSO NACIONAL, 1993, p. 19.30) - e a natureza desse tipo de emenda começou a mudar em 1994. Naquele ano, de acordo com o colegiado que atuou como "relator-geral", as emendas de relator foram propostas "com vistas ao aperfeiçoamento e adequação da lei orçamentária, para aqueles casos em que as indicações recaíram sobre ações não perfeitamente contempladas por emendas existentes" (CONGRESSO NACIONAL, 1994b).

O uso da emenda de relator-geral foi alterado no período de 1995 a 2006, quando essas emendas passaram a atender demandas dispersas de parlamentares e bancadas estaduais. Em outras palavras, o relator-geral deixou de utilizar essas emendas para atingir objetivos próprios e passou a usá-las para equacionar as pressões inerentes a este poderoso cargo na Comissão Mista de Orçamento. 0 artigo 23 da Resolução 2/1995 proíbe as emendas de relator-geral de incluírem subprojetos novos à lei orçamentária. Não obstante, o relator-geral por vezes adota maneiras informais de atender aos pedidos de parlamentares e bancadas. Um exemplo é descrito por Sanches (1998, p.9-10): "As 'Indicações de Bancada para Emendas de Relator', instituídas pelo Parecer Preliminar de 1996 e mantidas no

\footnotetext{
8 Pesquisa do autor no Arquivo do Senado Federal, Brasília, 21/5/2008.
} 
Parecer Preliminar de 1997, contornam as restrições às emendas de Relator-Geral, São uma forma de violação aos limites quantitativos fixados pela Resolução $n^{\circ}$ 2/95-CN para as emendas de bancada estadual. Em 1997. foram apresentadas cerca de 200 emendas de Relator-Geral, das quais pelo menos 25\% relativas à criação de novos subprojetos e subatividades".

Longe de significar atos unilaterais do relator-geral, as emendas de relator nos últimos anos têm sido um modo de atender às muitas demandas de parlamentares que não conseguiram influenciar o orçamento o suficiente a partir de suas emendas individuais e coletivas. Em 2007, por exemplo, o relator-geral incluiu um anexo de "metas e prioridades" que não constava da proposta enviada pelo Executivo. Uma notícia da época relata que "o anexo prevê gastos de $R \$ 534$ milhões em obras que atenderão as bases eleitorais dos parlamentares. O valor entrou sob a denominação de "emendas do relator-geral". O deputado João Leão (PP) confirmou que a maioria das emendas do anexo veio de membros da comissão. São deputados que há anos integram a comissão e passaram a exigir do relator-geral mais espaços para verbas para seus projetos. Para autorizar o relator, a comissão fez novas concessões legais. Um parecer técnico da consultoria de Orçamento do Congresso havia advertido, em outubro de 2007, que o relator não tinha poderes para apresentar tais emendas como se fossem suas. Mas esse inconveniente foi ignorado" 9 .

Vimos acima como o poder do relator-geral para emendar o orçamento foi usado de modo diferente no período dominado pelos "anões do orçamento" (1988. 1993) e no período em que a coalizão liderada pelo Executivo controlou o processo orçamentário (1994 em diante). Cabe agora analisar quais idéias sobre esta prerrogativa institucional circularam nos dois períodos críticos analisados, como e por quem elas foram defendidas, e por que foram adotadas ou não.

Até a Resolução 2/1994, utilizada apenas para regulamentar a tramitação do orçamento para 1995, as emendas de relator-geral não eram de modo algum limitadas. Para facilitar a vontade individual do legislador, por vezes corrupta, não havia nem mesmo a previsão de que essas emendas fossem publicadas para conhecimento dos outros parlamentares, assessores e demais interessados. A Resolução 2/1994 mostrou preocupação com esse ponto, ao exigir que "as emendas de Relator-Geral que venham a ser formuladas com vistas ao cumprimento de suas responsabilidades serão publicadas como parte do relatório, com indicação do proponente e dos respectivos fundamentos".

Ainda durante o período crítico de 1994-1995, a assessoria técnica do Congresso Nacional sugeriu que o relator-geral se limitasse a "consolidar as propostas dos Relatores Setoriais, promover as correções que se fizerem

9 "Contrabando no Orçamento dedica R\$534 milhões a emendas", Rubens Valente, Folha de S. Paulo, $25 / 2 / 2008$. 
necessárias e eventuais ajustes em cumprimento do disposto no parecer preliminar, vedada a apresentação de emendas que contenham matéria nova" (grifo meu).

Ambas as sugestões foram incorporadas na Resolução 2/1995. É um exemplo de parlamentares da coalizão defendendo menos prerrogativas para o relator-geral do processo orçamentário. O impacto do escândalo dos "anões do orçamento" para a formação de preferências é explícito neste ponto. O status quo foi mantido, em seus termos básicos, pela Resolução 1/2001.

Em seu projeto de resolução de 2005, Barros propôs: "Os relatores somente poderão apresentar emendas à programação da despesa com a finalidade de: I) corrigir erros e omissões de ordem técnica ou legal; II) recompor, total ou parcialmente, dotações canceladas, limitada a recomposição ao montante originalmente proposto no projeto; III) atender às especificações do parecer preliminar. É vedada a apresentação de emendas que tenham por objetivo a inclusão de subtítulos novos, bem como o acréscimo de valores a dotações constantes dos projetos". Com modificações mínimas, a Resolução 1/2006 manteve a proposta de Barros. O resultado foi a diminuição da autonomia do relator-geral para emendar o orçamento, mais até do que em 1995.

Se escândalos de corrupção foram fundamentais para diminuir o poder do relator-geral para emendar o orçamento, vale lembrar que os interesses dos parlamentares expostos acima, com base em Schickler (2001), também ocupam papel central na definição de instituições orçamentárias.

\section{Relação do Relator-Geral da CMO com relatores setoriais}

Considero agora um caso em que a corrupção teve papel secundário se comparado aos interesses relativos ao pertencimento à coalizão: a definição da relação do Relator-Geral com relatores setoriais da Comissão Mista de Orçamento.

As primeiras resoluções congressuais que trataram do processo orçamentário no período democrático - 1/1991, 1/1993 e 2/1995 - conferiam enormes prerrogativas ao relator-geral e pouquíssima relevância aos relatores setoriais. De acordo com a Resolução 1/1991, cabe ao relator-geral "adequar os pareceres setoriais aprovados, vedada qualquer modificação de parecer setorial, ressalvadas as alterações por ele propostas e aprovadas pelo Plenário da Comissão, bem como as decorrentes de destaques aprovados pela Comissão". A Resolução 2/1995 manteve este desenho básico, com modificações mínimas. Na prática, isso dava ao relator-geral o poder para mudar os relatórios setoriais à vontade.

De acordo com assessores técnicos do processo orçamentário no Senado Federal, "depois da Resolução de 1995, se o relator-geral quisesse pegar os 
relatórios setoriais, jogar no lixo e fazer tudo de novo, ele podia..."10. Não é de espantar, então, que os deputados federais Paulo Bernardo e Ricardo Barros tenham sugerido o fortalecimento das relatorias setoriais em relação ao Relator. Geral. Em março de 2005, Bernardo (PT, coalizão) sugeriu dar exclusividade ao acolhimento das despesas discricionárias pelas relatorias setoriais ou estabelecer limites e critérios à relatoria geral, no parecer preliminar, para remanejamento e cancelamentos na programação constantes dos relatórios setoriais.

Ricardo Barros foi um passo além. Sugeriu, também em março de 2005, na comissão criada para estudar reformas no processo orçamentário, dois pontos: i) vedação da possibilidade de o relator-geral alterar as dotações aprovadas nos relatórios setoriais, exceto para aumentar os seus valores e ii) definição, na resolução, dos percentuais da reestimativa de receita à disposição dos relatores setoriais e do relator-geral. Esse era o comportamento a esperar de Barros como membro da oposição.

Barros defendeu esses pontos para "terminar com o papel secundário das relatorias setoriais e a possibilidade de revisão, pela relatoria geral, sem critérios definidos, dos relatórios setoriais já aprovados" (CONGRESSO NACIONAL 2005, 31/3/2005, p.110-111). Afirmou, ainda, que "não podemos continuar repetindo o modelo atual, em que o relator setorial tem muito pouca importância no resultado final do que foi alocado, porque os valores que acabam ficando para o relator setorial são muito pequenos perto do conjunto das reestimativas feitas posteriormente à sua participação" (CONGRESSO NACIONAL 2005, 24/5/2005, p. 252). Em seu projeto de resolução, Barros propôs, entre diversos outros pontos, que: i) os relatores setoriais utilizarão como fontes de recursos para atendimento de emendas coletivas de apropriação aquelas definidas no parecer preliminar; ii) o Relator-Geral poderá propor em seu relatório acréscimos e cancelamentos nos valores das emendas coletivas de apropriação aprovadas nos pareceres setoriais, utilizando como fontes de recursos aquelas definidas no parecer preliminar e iii) fosse vedado ao Relator-Geral propor a aprovação de emendas com parecer setorial pela rejeição.

A decisão final da Resolução 1/2006 resultou em vitória completa para Barros neste quesito. Suas três propostas foram aprovadas. Decidiu-se que "os recursos líquidos destinados ao atendimento de emendas coletivas de apropriação terão o seguinte destino, observada a vinculação de fontes: i) 25\% para as emendas de Bancada Estadual; ii) 55\% aos Relatores Setoriais, para as emendas de Bancada Estadual e as de Comissão; iii) $20 \%$ ao Relator-Geral, para alocação, entre as emendas de Bancada Estadual e de Comissão, sendo que o Relator-Geral assegurará que o montante de recursos destinado ao atendimento de emendas de

\footnotetext{
${ }^{10}$ Entrevista com os consultores de Orçamento Carlos Marshall e Fernando Ramalho Bittencourt, Senado Federal, Maio/2008.
} 
Comissão não seja inferior a $15 \%$ do total dos recursos líquidos". Assim, a resolução assegura que uma parcela dos recursos será decidida de modo autônomo pelos relatores setoriais.

Barros comemorou, mais tarde, afirmando que "esta decisão eliminará a distorção repetida em muitos relatórios, em que o Relator-Geral aplicava em média 74\% dos recursos decorrentes de sucessivas reavaliações de receita. De 2002 a 2007, a maior participação do Relator-Geral foi de 80,68\% em 2003 e a menor foi em 2007, com 62,37\%. A partir desta nova resolução, caberá ao Relator-Geral 20\% dos recursos"11 (BARROS 2007, p.27).

Entre 1988 e 2008, onze decisões foram tomadas - algumas delas em mais de um momento - sobre a organização da etapa legislativa do processo orçamentário. Quatro das sete decisões sobre emendamento orçamentário tiveram alguma associação com escândalos de corrupção, algo que também afetou três das quatro decisões sobre a organização da Comissão Mista de Orçamento ${ }^{12}$ (ver Tabelas 2 e 3).

Algumas dessas decisões - especialmente com relação à prerrogativa de emendamento do relator-geral, a criação das emendas coletivas e a progressiva limitação de valor das emendas individuais - contribuíram para mudar a caracterização e efeitos da corrupção no processo orçamentário brasileiro. É importante retomar aqui a tipologia de Johnston (2005). Para ele, um dos tipos de corrupção é relacionado à "influência do mercado" e envolve esforço por parte de interesses privados (empresas, geralmente) para obter acesso e influência dentro de processos políticos bem institucionalizados. É o tipo de corrupção mais característico de democracias desenvolvidas. Outro tipo é a corrupção de um "cartel de elite". Ela ocorre dentro de, e ajuda a sustentar, redes de elites políticas, econômicas, burocráticas etc. Ajuda a manter a hegemonia dessas elites em um contexto de competição política crescente e instituições políticas moderadamente institucionalizadas.

As mudanças orçamentárias em 1995 e 2006 tornaram a corrupção no orçamento brasileiro mais semelhante à do tipo "influência de mercado" do que à do tipo "cartel de elite". Este movimento não é o único possível: o México, por exemplo, foi do "cartel de elite" à corrupção dos "oligarcas e clãs" (JOHNSTON 2005, p.193). Mas é um movimento condizente com o que Johnston (2005, p. 216) afirma acontecer com países cuja burocracia está se tornando mais capacitada e autônoma, bem como tendo os padrões de competição política mais bemordenados e organizados de acordo com regras mais estáveis. Podemos

\footnotetext{
11 Para mais detalhes sobre a decisão, ver Vieira (2008).

12 Outras instituições foram afetadas indiretamente pelo escândalos dos "anões do orçamento", mais notadamente o sistema de controle interno do Executivo (OLIVIERI, 2010) e o Tribunal de Contas da União (SPECK, 2000).
} 
OPINIÃO PÚBLICA, Campinas, vol. 17, no 1, Junho, 2011, p.137-162

argumentar que foi este o caso do Brasil nos anos noventa e que as reformas nas instituições orçamentárias refletem essa mudança de padrão.

\section{Considerações finais}

Este texto associou corrupção à centralização de instituições orçamentárias e fiscais. Isto é condizente com os achados de alguns estudos recentes sobre corrupção, segundo os quais instituições descentralizadas levam a menos corrupção (FISMAN e GATTI 2002; FAN et al, 2009). Este artigo mostrou também que os escândalos de corrupção podem, sob certas condições ressaltadas acima, resultar em mudanças institucionais que trazem mais accountability ao processo orçamentário.

O texto leva ainda, à reflexão sobre a volumosa literatura que associa bons resultados fiscais à centralização do processo orçamentário (ALESINA e PEROTTI, 1999; VON HAGEN, 2005), especialmente em sua etapa legislativa (CRAIN e MURIS, 1995; HELLER, 1997). Caso o processo seja centralizado, mas, ao mesmo tempo, a aplicação das regras formais seja falha e regras informais sejam bastante utilizadas pelos atores envolvidos no orçamento, como foi o caso do Brasil no período dos "anões do orçamento", esta centralização pode ter efeitos inesperados e perversos.

\section{Referências Bibliográficas}

ABRAMO, C. W. "Percepções pantanosas: a dificuldade de medir a corrupção", Novos Estudos Cebrap, n.3, p.33-37, 2005.

ALESINA, A. \& PEROTTI, R. "Budget Deficits and Budget Institutions", In: POTERBA, J. \& VON HAGEN, J. (Eds.) Fiscal Institutions and Fiscal Performance. Chicago:

University of Chicago Press, 1999.

BARBOSA, L. B. As prioridades fixadas na Lei de Diretrizes Orçamentárias para a Administração Pública Federal importam? Dissertação (mestrado em Ciência Política), Universidade de Brasília, 2006.

BARDHAN, P. "Corruption and development: a review of issues", Journal of Economic Literature, v.35, p. 1320-1346, 1997.

BARROS, R. De olho no dinheiro do Brasil. Brasília: Editora 24x7 Cultural, 2007. 
CAPOCCIA, G. \& K; DANIEL, R. "The study of critical junctures: theory, narrative, and counterfactuals in historical institutionalism", World Politics, v.59, p.341-369, 2007.

CARVALHO, N. R. E no início eram as bases: geografia política do voto e comportamento legislativo no Brasil. Rio de Janeiro: Ed. Revan, 2003.

CHANG, E. "Electoral Incentives for Political Corruption under Open-List Proportional Representation", Journal of Politics, v.67, n. 3, p.716-730, 2005.

CHANG, E. \& GOLDEN, M. "Electoral Systems, District Magnitude and Corruption", British Journal of Political Science, v. 37, n. 1, p.115-37, 2007.

CONGRESSO NACIONAL. Comissão Mista de Orçamento. Relação Geral dos Pareceres: Emendas Aprovadas. Brasília: Congresso Nacional, 13/12/1990.

. Sistema de Informações Orçamentárias. Relatório de Emendas Aprovadas. Brasília, Congresso Nacional, 26/3/1993.

. Parecer Preliminar de 1994. Parecer Final da Comissão Mista de Orçamento sobre o Projeto de Lei n. 3 de 1994 (CN) de iniciativa do Poder Executivo que "estima a receita e fixa a despesa da União para o exercício financeiro de 1995". Autores: Gilberto Miranda e diversos relatores-adjuntos, que são: senador Carlos Patrocínio; deputado João Faustino; deputado Roberto Balestra; deputado Vadão Gomes; deputado João Almeida; deputado Oswaldo Coelho; senador Ronan Tito. Brasília, Congresso Nacional, 1994b.

. Relatório da CPI do Orçamento. Brasília, Congresso Nacional, 1994a, volume II, depoimento tomado em 22/10/1993.

- Notas taquigráficas da Comissão Mista destinada a propor a reestruturação do processo orçamentário. Brasília, Congresso Nacional, 2005, mimeo, 282 pgs.

Comissão Parlamentar Mista de Inquérito "das Ambulâncias". Relatório dos trabalhos da CPMI das Ambulâncias. Brasília: Congresso Nacional, Agosto de 2006.

CRAIN, W. M. \& MURIS, T. J. "Legislative organization of fiscal policy", Journal of Law and Economics, v. 38, p.311-333, n.2, 1995.

FAN, S. C.; LIN, C.; TREISMAN, D. "Political decentralization and corruption: Evidence from around the world", Journal of Public Economics, v. 93, p.14-34, n. 1-2, 2009.

FIGUEIREDO, A. \& LIMONGI, F. Executivo e Legislativo na nova ordem constitucional. Rio de Janeiro: Ed. FGV, 1999. 
OPINIÃO PÚBLICA, Campinas, vol. 17, no 1, Junho, 2011 , p.137-162 2008.

. Política orçamentária no presidencialismo de coalizão. Rio de Janeiro: Ed. FGV,

FISMAN, R. \& GATTI, R. "Decentralization and corruption: evidence across countries", Journal of Public Economics, v. 83, n. 3, 2002, p.325-345.

FISMAN, R. \& M, E. Economic gangsters: corruption, violence, and the poverty of nations. Princeton: Princeton University Press, 2008.

FRIED, B. J; LAGUNES, P. \& VENKATARAMANI, A. "Corruption and inequality at the cross road: a Multimethod Study of Bribery and Discrimination in Latin America", Latin American Research Review, v. 45, n. 1, 2010, p.76-97.

GAMBETTA, D. "Corruption: an analytical map", In: KREIKE, E. \& JORDAN, W. C. (eds.) Corrupt Histories. New York: University of Rochester Press, 2004.

GERRING, J. \& THACKER, S. "Political institutions and corruption: the role of unitarism and parliamentarism", British Journal of Political Science, v.34, p. 295.330, 2004.

GLAESER, E. \& GOLDIN, C. "Corruption and Reform: An Introduction", In: GLAESER, E. \& GOLDIN, C. (eds.) Corruption and Reform: Lessons from America's Economic History. Chicago: University of Chicago Press, 2006.

GOLDEN, M. "Electoral connections: the effects of the personal vote on political patronage, bureaucracy and legislation in postwar Italy", British Journal of Political Science, v.33, n. 2, p. 189-212, 2003.

GOLDEN, M. \& PICCI, L. "Proposal for a New Measure of Corruption, Illustrated with Italian Data", Economics \& Politics, v. 17, n. 1, p.37.75, 2005.

HELLER, W. B. "Bicameralism and budget deficits: the effect of parliamentary structure on government spending", Legislative Studies Quarterly, v.22, n.4, p. 485. 516, 1997.

HUBER, J. \& SHIPAN, C. Deliberate Discretion? The institutional foundations of bureaucratic autonomy. New York: Cambridge University Press, 2002.

HUNTER, W. "The Partido dos Trabalhadores: Still a Party of the Left?", In: KINGSTONE, P. R. \& POWER, T. (eds.) Democratic Brazil Revisited. Pittsburgh: University of Pittsburgh Press, p. 15-32, 2008.

ISAKSEN, J. The budget process and corruption. Bergen: Chr. Michelsen Institute. U4 Issue 3, 2005. 
JOHNSTON, M. Syndromes of corruption: wealth, power, and democracy. Cambridge: Cambridge University Press, 2005.

KLITGAARD, Robert. Controlling Corruption. Berkeley: University of California Press, 1988.

KRIEGER, G. RODRIGUES, F. \& BONASSA, E. Os donos do Congresso. São Paulo: Ática, 1994.

KUNICOVÁ, J. \& ROSE.ACKERMAN, S. "Electoral rules and constitutional structures as constraints on corruption", British Journal of Political Science, v.35, n. 4, p.573. 606, 2005.

LAMBSDORFF, J. G. The institutional economics of corruption and reform: theory, evidence, and policy. New York: Cambridge University Press, 2007.

MÉNDEZ, F. \& SEPÚLVEDA, F. "What do we talk about when we talk about corruption", Journal of Law, Economics, and Organization, 2009, forthcoming.

NYE, J. S. "Corruption and political development: a cost-benefit analysis", American Political Science Review, v.61, p.417-427, n. 2, 1967.

OLIVIERI, C. "Monitoramento das políticas públicas e controle da burocracia: o sistema de controle interno do Executivo federal brasileiro", In: LOUREIRO, M. R.; ABRUCIO, F. \& PACHECO, R. (Orgs.). Burocracia e política no Brasil: desafios para o Estado democrático no século XXI. Rio de Janeiro: Ed. FGV, 2010, p. 149-180.

PEREIRA, C. \& RENNÓ, L. "Successful reelection strategies in Brazil: the electoral impact of distinct institutional incentives", Electoral Studies, v. 22, p. 425-448, 2003.

PEREZINO, L. F. M. A preponderância do Poder Executivo no processo orçamentário. Brasília: Senado Federal/Unilegis, 2008.

PINHEIRO, V. C. "Inflação, poder e processo orçamentário no Brasil”, Revista do Serviço Público, v. 120, n.1, p. 141-164, 1996.

ROSE-ACKERMAN, S. (Ed.) International Handbook on the Economics of Corruption. Massachussets: Edward Elgar, 2006.

. Corruption and government: causes, consequences, and reform. New York: Cambridge University Press, 1999.

SANCHES, O. "A atuação do poder legislativo no orçamento: problemas e imperativos de um novo modelo", Revista de Informação Legislativa, v.35, n.138, 1998. 
SCHICKLER, E. Disjointed Pluralism: Institutional Innovation and the Development of the U.S. Congress. Princeton: Princeton University Press, 2001.

SHLEIFER, A. \& VISHNY, R. "Corruption", Quarterly Journal of Economics, v.8, p.599. 617, n.3, 1993.

SPECK, B. Inovação e Rotina no Tribunal de Contas da União: o Papel da Instituição Superior de Controle Financeiro no Sistema Político-Administrativo do Brasil. São Paulo: Fundação Konrad Adenauer, 2000.

TAYLOR, M. "Corruption, Accountability Reforms, and Democracy in Brazil", In: BLAKE, C. H. \& MORRIS, S. D. Corruption and Democracy in Latin America. Pittsburgh: Pittsburgh University Press, p. 150-168, 2009.

TRANSPARENCY INTERNATIONAL. Global Corruption Report 2007: corruption in judicial systems. Cambridge: Cambridge University Press, 2007.

TREISMAN, D. "What Have We Learned About the Causes of Corruption From Ten Years of Cross-National Empirical Research?", Annual Review of Political Science, v. 10, p. 211-244, 2007.

VIEIRA, V. C. As inovações no processo legislativo das leis orçamentárias à luz da Resolução 1/2006 do Congresso Nacional. Monografia apresentada no curso de Especialização em Orçamento Público da Unilegis. Brasília, DF, 2008.

VON HAGEN, J. "Budgeting institutions and public spending", In: SHAH, A. (Ed.). Fiscal Management. Washington D.C: World Bank, p. 1-29, 2005.

Sérgio Praça - srpraca@uol.com.br

Recebido para publicação em dezembro de 2010. Aprovado para publicação em março de 2011. 